Revista Geográfica Digital. IGUNNE - Instituto de Geografía. Facultad de Humanidades. UNNE. Año 12. Nº

23. Enero - Junio 2015. ISSN 1668-5180 Resistencia, Chaco, Argentina

\title{
PERFIL DEMOGRÁFICO DE LAS LOMADAS ARENOSAS EN EL TRIÁNGULO NOROCCIDENTAL DE LA PROVINCIA DE CORRIENTES (ARGENTINA): ANÁLISIS EN DOS MOMENTOS CENSALES (2001 y 2010).
}

Prof. Elsie Araseli Ojeda

Becaria de la Secretaria General de Ciencia y Técnica

Instituto de Investigaciones Geohistóricas (CONICET-UNNE)

E-mail: araseliojeda@hotmail.com

Dra. Blanca Elizabeth Ponce

Prof. Auxiliar en Geografía y Sociedad

Departamento de Geografía. Facultad de Humanidades UNNE

Becaria del CONICET

Instituto de Investigaciones Geohistóricas (CONICET-UNNE)

\section{Resumen}

La región de Lomadas Arenosas corresponde al abanico aluvial del sistema del río Paraná, el cual cubre el noroeste y suroeste de la provincia de Corrientes (Argentina). Este medio natural proporciona a la población, recursos para la satisfacción de sus necesidades. Por este motivo, es importante conocer su estructura demográfica, debido a las importantes consecuencias que genera en el ámbito económico y social, así como también, para ser utilizado en futuros estudios de evaluación del impacto de la población sobre dichos recursos.

El área en estudio está compuesta por 17 departamentos que se sitúan en el triángulo noroccidental de la provincia de Corrientes. En el presente trabajo, nos centraremos únicamente en describir la evolución demográfica y la estructura por edad y sexo de la población. Esta última, es el resultado de las características pasadas de la fecundidad, mortalidad y migración.

\section{Palabras Claves}

Región de Lomadas Arenosas; estructura por edad y sexo; evolución demográfica

\section{DEMOGRAPHIC PROFILE OF THE LOMADAS ARENOSAS AT THE NORTHWEST TRIANGLE OF THE PROVINCE OF CORRIENTES (ARGENTINA): ANALYSIS TAKEN FROM TWO CENSES (2001 AND 2010)}

\section{Summary}

The Lomadas Arenosas region corresponds to the alluvial fan of the Paraná river system, which covers the northwest and southwest region of the province of Corrientes (Argentina). This environment provides resources to the population to satisfy their needs. For this reason, is important to know its demographic structure, due to the significant impact it has on the economic and social sphere, as well as to be used in future studies to evaluate the impact of the population has on those resources. The area of study is made of consists 17 departments which are located in the northwest triangle of the province of Corrientes. In this paper, we are going to on describing the demographic evolution and the structure of the age and sex of the population. The latter is the result of past patterns of fertility, mortality and migration.

\section{Key Words}

Lomadas Arenosas region; structure by age and sex; demographic evolution.

Publicado en formato digital: Prof. Elsie Araseli Ojeda y Dra. Blanca Elizabeth Ponce. PERFIL DEMOGRÁFICO DE LAS LOMADAS ARENOSAS EN EL TRIÁNGULO NOROCCIDENTAL DE LA PROVINCIA DE CORRIENTES (ARGENTINA): ANÁLISIS EN DOS MOMENTOS CENSALES (2001 y 2010) Revista Geográfica Digital. IGUNNE. Facultad de Humanidades. UNNE. Año 12. No 23. Enero - Junio 2015. ISSN 1668-5180 Resistencia, Chaco.

En: http://hum.unne.edu.ar/revistas/geoweb/default.htm 
Revista Geográfica Digital. IGUNNE - Instituto de Geografía. Facultad de Humanidades. UNNE. Año $12 . N^{\circ}$ 23. Enero - Junio 2015. ISSN 1668-5180 Resistencia, Chaco, Argentina

\section{Introducción}

Se denomina "Región de Lomadas Arenosas" al abanico aluvial o "mega abanico" formado por el sistema del río Paraná, que cubre el noroeste y parte del suroeste de la provincia de Corrientes (Argentina), así como parte de la república del Paraguay. En la provincia antes mencionada, la integran los siguientes departamentos: Bella Vista, Berón de Astrada, Capital, Itatí, San Cosme, San Roque, Lavalle, Goya, Esquina, Mburucuyà, Saladas, General Paz, Concepción, San Miguel, Empedrado, Ituzaingó y San Luis del Palmar (ver Mapa $N^{\circ} 1$ ).

Esta región presenta una distancia lineal de alrededor de $260 \mathrm{~km}$ de longitud en sentido norte-sur y $500 \mathrm{~km}$ de ancho, que se mantuvo estable durante todo el Cuaternario Superior. Por otra parte, el río Paraná fue creando cursos relativamente estables, los que finalmente fueron abandonados por la corriente principal y se convirtieron en pantanos. Es así que extensos depósitos fluviales, producidos por salidas de derrame durante las fases climáticas secas en el Cuaternario Superior, se intercalaron entre los cursos abandonados (Iriondo y Paira, 2007).

Los antiguos abanicos fueron pediplanizados y luego excavados en ciclos de erosión más modernos condicionando todo el escurrimiento actual en las cañadas, esteros y ríos que se disponen en forma divergente a partir de la localidad de Ituzaingó (Popolizio 1984).

Frenguelli (1924) describe a la región como una llanura ondulada cuya altura media es de aproximadamente 60 metros sobre el nivel del mar y de 15 a 20 metros sobre el nivel del río Paraná. Las ondulaciones, de pendientes muy suaves, de dorso ancho y chato, forman, en líneas generales, largos cordones paralelos entre sí y con rumbo general aproximado de suroeste a noreste. Las elevaciones están separadas por depresiones longitudinales, de ancho variable pero siempre poco pronunciadas. Depresiones menores, de dirección transversal, a menudo subdividen a las lomadas en lomas bajas que, pocas veces se levantan sobre el nivel general del territorio. Sobre el ancho dorso de las lomadas es frecuente hallar pequeñas depresiones de contornos circulares, poco acentuadas y de fondo llano. Presentan características de "bandejas" o más raramente de "palangana". Todas estas depresiones están llenas de agua, formando lagunas y esteros. El número de estas cuencas, su extensión y profundidad varían en relación con la pluviosidad, muchas cuencas menores, durante la estación seca (invierno) y, sobre todo, durante períodos de sequía prolongada, se secan completamente, mientras las mayores se reducen considerablemente.

El carácter de la vegetación confirma y pone de relieve las variaciones mencionadas: en las cuencas temporarias no existe una verdadera vegetación acuática, la cual abunda en las cuencas permanentes, cubriéndolas parcial o completamente (Carnevalli, 1994).

En síntesis, estas formas han condicionado fuertemente el escurrimiento, los suelos y la vegetación y por consiguiente la ocupación urbana y rural de esas áreas (Popolizio 1984).

En este contexto nos preguntamos ¿Cómo ha sido la evolución de la población en los diferentes departamentos que conforman la región? ¿Cuál es su estructura demográfica y si existe algún patrón en el comportamiento de dichos departamentos?

Dentro de este marco, el presente trabajo tiene por objetivo principal describir la evolución demográfica y la estructura por edad y sexo de la población residente en los 17 departamentos, durante los dos últimos momentos censales. Esta información será de sumo interés para futuras investigaciones donde evaluaremos el impacto de la población sobre dichos recursos.

La composición de una población por edad y sexo es la variable demográfica básica para cualquier estudio de población ya que la misma tiene decisiva importancia por sus repercusiones de orden social y económico y, es el resultado de tendencias pasadas de la fecundidad, la mortalidad y la migración.

Por su parte, el análisis de las variaciones espaciales y temporales del poblamiento, proporciona una base adecuada para la atención de numerosos aspectos referidos a la planificaciones urbana, de los servicios, de las viviendas, de las necesidades de transporte y comunicación, como así también a problemas derivados del crecimiento demográfico que influyen, directa o indirectamente sobre la economía de la región (Foschiatti, 1992).

Publicado en formato digital: Prof. Elsie Araseli Ojeda y Dra. Blanca Elizabeth Ponce. PERFIL DEMOGRÁFICo DE LAS LOMADAS ARENOSAS EN EL TRIÁNGULO NOROCCIDENTAL DE LA PROVINCIA DE CORRIENTES (ARGENTINA): ANÁLISIS EN DOS MOMENTOS CENSALES (2001 y 2010) Revista Geográfica Digital. IGUNNE. Facultad de Humanidades. UNNE. Año 12. No 23. Enero - Junio 2015. ISSN 1668-5180 Resistencia, Chaco.

En: http://hum.unne.edu.ar/revistas/geoweb/default.htm 


\section{Ubicación Geográfica de la Región de Lomadas Arenosas (Provincia de Corrientes. Argentina)}

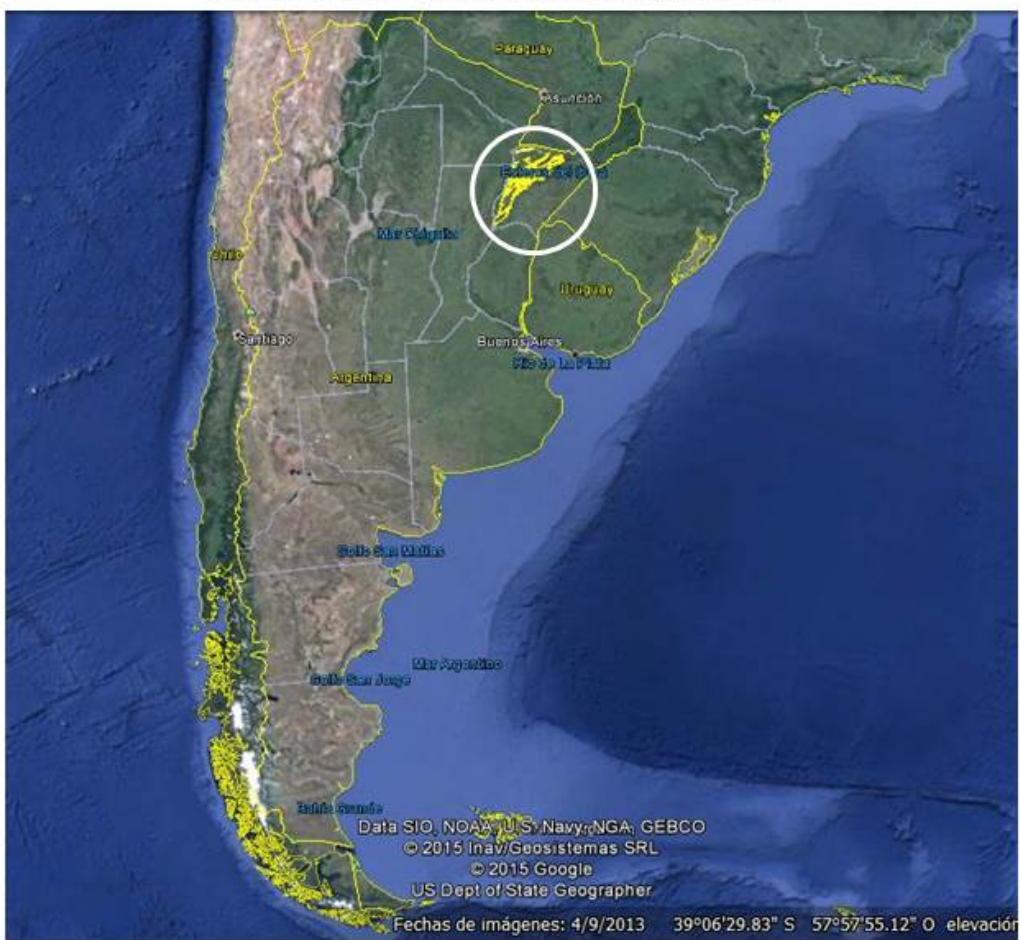

Fuente: elaboración propia en base a imagen de Google Earth. Año 2015

Mapa $N^{\circ} 1$

\section{Materiales y Métodos}

En un primer momento se recurrió a la búsqueda de datos estadísticos proporcionados por los censos de Población, Hogar y Vivienda correspondientes a los años 2001 y 2010. Al mismo tiempo, con la finalidad de estudiar la evolución de la población en los departamentos antes mencionados, se utilizaron los datos censales de los años 1970, 1980 y 1991.

En una segunda instancia, a través del software Redatam R+SP, se obtuvieron las variables necesarias para el análisis.

Una vez generada la base de datos, se procedió al tratamiento y normalización de la información.

Posteriormente se trabajó con Excel para la generación de gráficos y Arc GIS para la elaboración de la cartografía pertinente. Por otra parte, las pirámides de población se confeccionaron a partir de la planilla de cálculo PYRAMID del programa PAS (Population Analysis System. U.S. Census Bureau). El análisis de ellos, a la luz de la bibliografía recabada para esta ocasión, permitió la elaboración de las conclusiones.

Publicado en formato digital: Prof. Elsie Araseli Ojeda y Dra. Blanca Elizabeth Ponce. PERFIL DEMOGRÁFICO DE LAS LOMADAS ARENOSAS EN EL TRIÁNGULO NOROCCIDENTAL DE LA PROVINCIA DE CORRIENTES (ARGENTINA): ANÁLISIS EN DOS MOMENTOS CENSALES (2001 y 2010) Revista Geográfica Digital. IGUNNE. Facultad de Humanidades. UNNE. Año 12. No 23. Enero - Junio 2015. ISSN 1668-5180 Resistencia, Chaco.

En: http://hum.unne.edu.ar/revistas/geoweb/default.htm 
Revista Geográfica Digital. IGUNNE - Instituto de Geografía. Facultad de Humanidades. UNNE. Año $12 . N^{\circ}$ 23. Enero - Junio 2015. ISSN 1668-5180 Resistencia, Chaco, Argentina

\section{Antecedentes}

Entre los aportes realizados sobre las condiciones geomorfológicas del área, debemos destacar los trabajos del Ing. Popolizio $(1984,1986,1989)$ dichas publicaciones son de carácter descriptivo en función de las formas resultantes del paisaje.

En relación a la problemática de crecimiento urbano y demográfico de la Provincia de Corrientes, se puede destacar el trabajo de Foschiatti de Dell' Orto (1980) en su trabajo "El Crecimiento Urbano en las provincias del Litoral Fluvial Argentino". En el mismo la autora analiza el proceso de formación de la red urbana, el grado y el sentido de la urbanización en las provincias de Corrientes, Chaco, Entre Ríos, Formosa, Misiones y Santa Fe, visualizando especialmente los cambios ocurridos entre los años 1895 y 1970.

Asimismo se puede destacar el Atlas Geográfico de la Provincia de Corrientes, confeccionado por el Instituto de Geografía de la Facultad de Humanidades de la UNNE, el cual analiza las actividades económicas realizadas en la provincia, el Tomo IV (2001) se encarga de analizar las actividades primarias y el Tomo V (2004) las actividades secundarias y terciarias.

Finalmente debemos nombrar la obra Corrientes en Cifras. Recopilación y compilación estadística para la interpretación de la situación actual (Ramírez, et. al. 2013). El mismo recopila y procesa datos estadísticos relevados y producidos por diferentes organismos estatales de la provincia de Corrientes, tales como Dirección de Estadística y Censos; Dirección de Planificación y Estadísticas de Salud del Ministerio de Salud Pública; Vialidad Nacional, Vialidad Provincial y Tribunal Electoral.

\section{Resultados}

\section{Evolución de la población desde 1970 a 2010}

La provincia de Corrientes, con una tradición ganadera -que la sustentó económicamente desde la época colonial- permitió una ocupación del espacio muy temprana, aún cuando en las demás provincias no había el menor indicio de efectivizarse un poblamiento estable. Ni la agricultura, ni la industria, tuvieron una participación activa en el desarrollo económico provincial, aunque existieron algunos intentos que sólo prosperaron en el área oriental, con la yerba y el té.

En cuanto a las migraciones, la mayor parte de los departamentos se caracterizan por expulsar a la población rural, provocando un vaciamiento en ese ámbito, ocasionado por los numerosos problemas derivados de las deficiencias en los sistemas de producción y en el estancamiento económico y social (Foschiatti, 1992).

En términos generales, los 17 departamentos que integran la Región de Lomadas Arenosas, se caracterizan por un crecimiento continuo. No obstante, podemos identificar algunas diferencias en su interior.

En un primer orden podemos mencionar a Capital, donde se produjo el mayor crecimiento durante el periodo analizado (137.823 habitantes en 1970 y 358.223 habitantes en el 2010). Este crecimiento se vio impulsado principalmente por los procesos inmigratorios, la razón se encuentra más en la crisis del interior provincial -que expulsa población- que en el desarrollo económico, social o cultural. (Foschiatti, 1990).

En segundo lugar se destaca Bella Vista con un incremento del 81\% entre los años 1970 y 2010 . De la misma manera podemos nombrar a San Cosme, Itatí y Lavalle, los cuales registraron un incremento del 77\%, 59\% y $55 \%$ respectivamente. En este sentido, Foschiatti (1992) expresa que el ritmo de incremento de la población es el resultado de los efectos ocasionados por los desplazamientos demográficos y no, necesariamente, por el incremento natural, aunque actúa como un atenuante permanente (Ver Gráfico $N^{\circ} 1$ ).

En contrapartida, los departamentos que tuvieron un menor crecimiento demográfico fueron Empedrado, Berón de Astrada y General Paz (5\%, 10\% y 6\%).

Publicado en formato digital: Prof. Elsie Araseli Ojeda y Dra. Blanca Elizabeth Ponce. PERFIL DEMOGRÁFICo DE LAS LOMADAS ARENOSAS EN EL TRIÁNGULO NOROCCIDENTAL DE LA PROVINCIA DE CORRIENTES (ARGENTINA): ANÁLISIS EN DOS MOMENTOS CENSALES (2001 y 2010) Revista Geográfica Digital. IGUNNE. Facultad de Humanidades. UNNE. Año 12. № 23. Enero - Junio 2015. ISSN 1668-5180 Resistencia, Chaco.

En: http://hum.unne.edu.ar/revistas/geoweb/default.htm 
Tanto en el siglo XX como en inicios del XXI fueron los acontecimientos económicos y los requerimientos de la sociedad, los que a través de los movimientos de la población -en procura de un mejor nivel de vida- deciden los rasgos demográficos provinciales (Foschiatti, 2013).

Con respecto a la densidad de la población de la región, ésta varió entre los años 1970 y 2010 de 8,91 a 16,20 habitantes por $\mathrm{Km}^{2}$. La mayor densidad la registra Capital $\left(716,45\right.$ habitantes por $\mathrm{Km}^{2}$ en el año 2010) y la menor densidad la tiene General Paz (2,97 habitantes por $\mathrm{Km}^{2}$ en el año 2010).

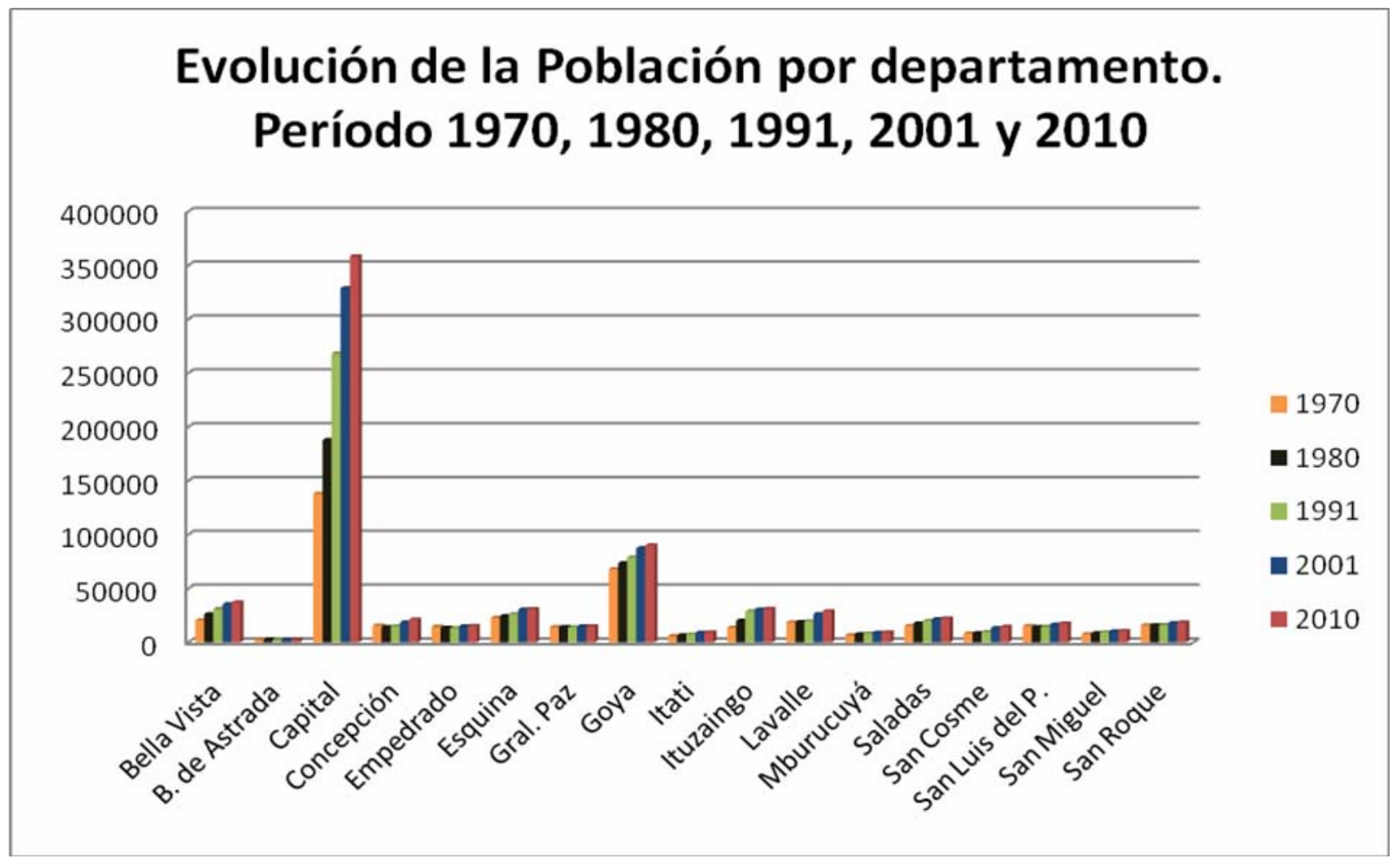

Fuente: Elaboración propia en base a Censos 1970, 1980, 1991, 2001 y 2010.

Gráfico No 1

\section{Estructura por edad y sexo de la población}

\section{Pirámides de Población}

La estructura por edad y sexo de la población son componentes que participan directamente en la dinámica de la población. Se la representa gráficamente a través de la pirámide de población, la cual muestra la estructura por edad y sexo de la población en un momento dado. En esta oportunidad, representaremos las pirámides de los departamentos que conforman la Región de Lomadas Arenosas, en dos momentos censales (2001 y 2010).

En el año 2001, observamos en términos generales que los departamentos que conforman nuestro espacio de estudio, se caracterizan por presentar una pirámide de forma triangular, que recibe la denominación de Expansiva, por poseer una base ancha y un angostamiento progresivo y regular hasta la cúspide. Este tipo de pirámides es propio de poblaciones jóvenes, donde la alta proporción de niños y jóvenes son el resultado de una alta natalidad. Por su parte, su rápido estrechamiento es

Publicado en formato digital: Prof. Elsie Araseli Ojeda y Dra. Blanca Elizabeth Ponce. PERFIL DEMOGRÁFICO DE LAS LOMADAS ARENOSAS EN EL TRIÁNGULO NOROCCIDENTAL DE LA PROVINCIA DE CORRIENTES (ARGENTINA): ANÁLISIS EN DOS MOMENTOS CENSALES (2001 y 2010) Revista Geográfica Digital. IGUNNE. Facultad de Humanidades. UNNE. Año 12. NN 23. Enero - Junio 2015. ISSN 1668-5180 Resistencia, Chaco.

En: http://hum.unne.edu.ar/revistas/geoweb/default.htm 
Revista Geográfica Digital. IGUNNE - Instituto de Geografía. Facultad de Humanidades. UNNE. Año $12 . N^{\circ}$ 23. Enero - Junio 2015. ISSN 1668-5180 Resistencia, Chaco, Argentina

consecuencia de una elevada mortalidad y su cúspide angosta muestra la baja proporción de adultos mayores.

Podríamos distinguir dos grupos entre nuestras unidades de análisis, según sea su composición por sexo en los primeros grupos etarios. Por un lado, tenemos a los departamentos de Capital, Goya, Saladas y San Roque (ver Gráfico $N^{\circ} 6,12,20$ y 26) con un predominio de varones y, por otro, a los departamentos de Concepción, General Paz y San Miguel con un predominio de mujeres (ver Gráfico $\mathrm{N}^{\circ} 8,30$ y 24). Sin embargo, en la medida que aumentan las edades, aumenta la proporción de mujeres, principalmente en la población mayor de 65 años; con excepción de San Roque que posee los mismos porcentajes para ambos sexos.

Sobresaliéndose en este grupo de departamentos se encuentra Berón de Astrada, (ver Gráfico $\mathrm{N}^{\circ} 4$ ) con una pirámide de forma irregular, donde se advierte una notable falta de población en el grupo correspondiente a las edades económicamente activas. Esta pérdida de población podría deberse a las emigraciones producidas hacia el departamento Capital, donde las diferentes oportunidades que ofrece la ciudad, como las universidades públicas y/o privadas e institutos terciarios, actúan como polo atrayente, no solo de la provincia sino de la región. De igual manera, podría estar relacionado a la mayor oferta en el mercado laboral.

Esta búsqueda de mejores condiciones laborales se relaciona con las transformaciones producidas por el gobierno neo - liberal -durante la década de los 90 y que culmina con la crisis del 2001introdujo fuertes transformaciones en la estructura del mercado laboral y el comportamiento de los diferentes grupos que conforman la sociedad, aunque posteriormente algunas de ellas se han modificado y sobrevenido a otras, a partir del proceso de recuperación económica iniciado en el 2003. En la primera etapa el signo característico fue el deterioro del sistema de empleo y el proceso creciente de precarización laboral, que se tradujo en altas cifras de desempleo, pobreza y exclusión. Durante la segunda y aunque mejoraron los indicadores más críticos se han mantenido e incluso acentuado los índices de precarización e informalidad en el trabajo (Pérez Rubio 2013).

Al mismo tiempo observamos altos porcentajes en el grupo de los adultos mayores, (mujeres $12 \%$ y varones $10 \%$ ) marcando la diferencia del resto de los departamentos estudiados.

Para el año 2010, esos caracteres que en el 2001 indicaban una incipiente madurez de la población, producen un cambio que se manifiesta en una pirámide del tipo Campana, donde el estrechamiento de la base es la consecuencia de una natalidad en reducción, mientras que su cúspide se va engrosando producto del aumento del peso relativo de la población en edades avanzadas.

Con excepción de Berón de Astrada y Concepción (ver Gráfico № 5 y 9), se vuelve a evidenciar el patrón de predominio de los varones en los primeros grupos etarios.

Con respecto a la población económicamente activa, existe un predominio de mujeres en los departamentos de Bella Vista, Capital, Goya, Saladas, San Cosme y San Roque (ver Gráfico $N^{\circ} 3,7$, 13, 21, 23 y 27). En relación a lo expresado anteriormente, Pérez Rubio (2013) afirma que un alto porcentaje de mujeres trabajan en el servicio doméstico; acordando con las características tradicionales de la región y las escasas oportunidades que ofrece el sector productivo, la posibilidad de contar con personas que se hagan cargo del trabajo de reproducción mediante una retribución no muy alta, es frecuente en esta región.

En concordancia con el tipo de pirámide que caracteriza a esta región, observamos un aumento en los porcentajes de los grupos etarios mayores de 65 años, destacándose nuevamente la población femenina.

En este contexto sobresale nuevamente el caso de Berón de Astrada, el cual presenta los mismos patrones de irregularidad mencionados para el año 2001 (ver Gráfico №5).

Publicado en formato digital: Prof. Elsie Araseli Ojeda y Dra. Blanca Elizabeth Ponce. PERFIL DEMOGRÁFICo DE LAS LOMADAS ARENOSAS EN EL TRIÁNGULO NOROCCIDENTAL DE LA PROVINCIA DE CORRIENTES (ARGENTINA): ANÁLISIS EN DOS MOMENTOS CENSALES (2001 y 2010) Revista Geográfica Digital. IGUNNE. Facultad de Humanidades. UNNE. Año 12. № 23. Enero - Junio 2015. ISSN 1668-5180 Resistencia, Chaco.

En: http://hum.unne.edu.ar/revistas/geoweb/default.htm 
Pirámides de población de los departamentos de la Región de Lomadas Arenosas de la Provincia de Corrientes. Años 2001 y 2010.

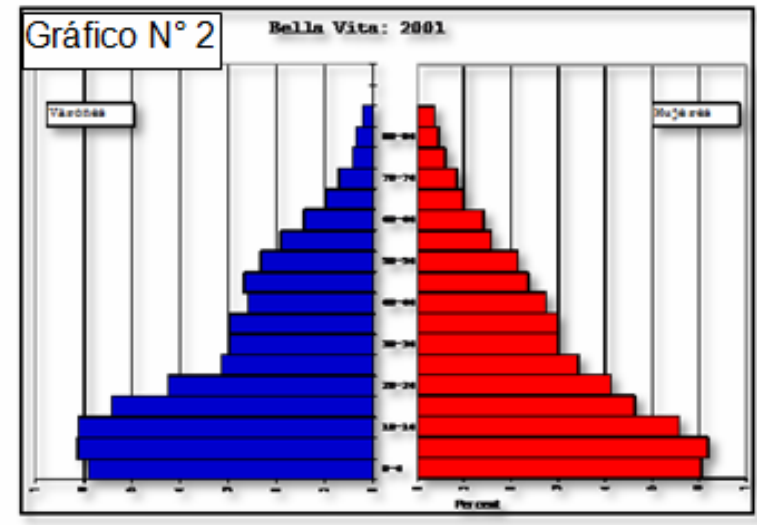

Elaboración propia en base a los datos del INDEC 2001

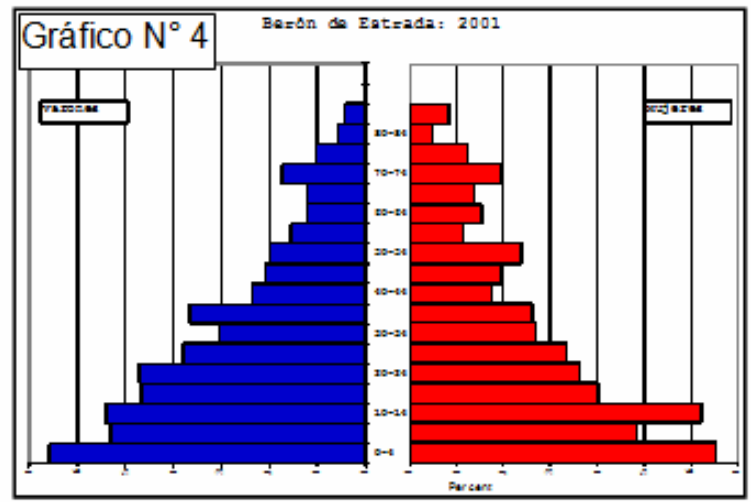

Elaboración propia en base a los datos del INDEC 2001

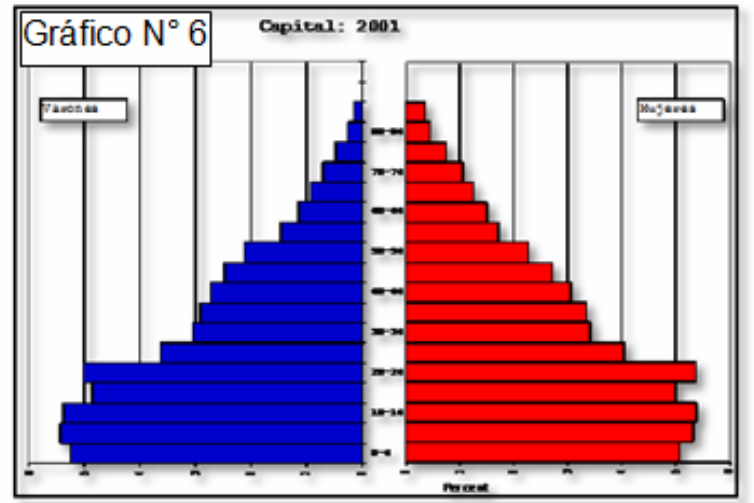

Elaboración propia en base a los datos del INDEC 2001

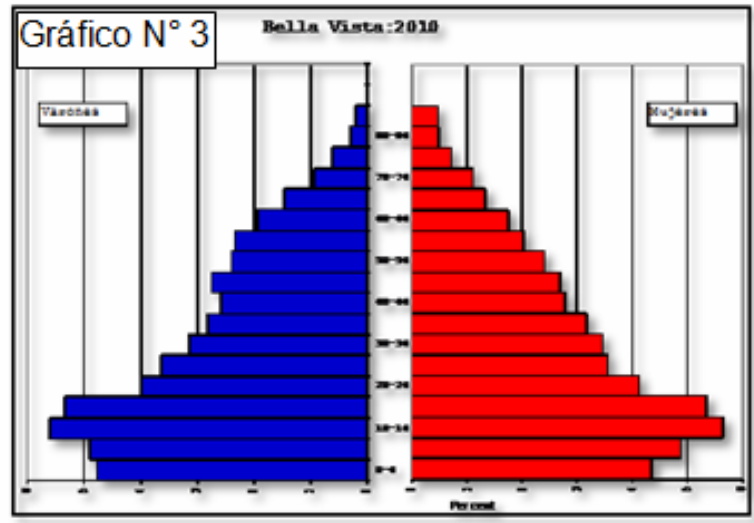

Elaboración propia en base a los datos del INDEC 2010

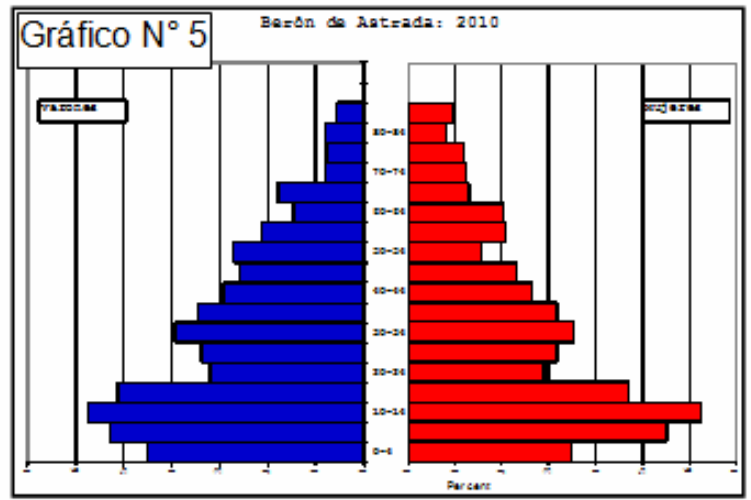

Elaboración propia en base a los datos del INDEC 2010

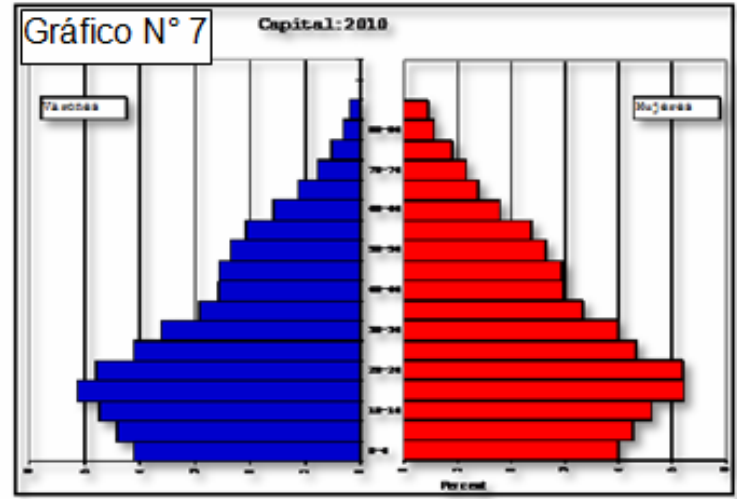

Elaboración propia en base a los datos del INDEC 2010

Publicado en formato digital: Prof. Elsie Araseli Ojeda y Dra. Blanca Elizabeth Ponce. PERFIL DEMOGRÁFICO DE LAS LOMADAS ARENOSAS EN EL TRIÁNGULO NOROCCIDENTAL DE LA PROVINCIA DE CORRIENTES (ARGENTINA): ANÁLISIS EN DOS MOMENTOS CENSALES (2001 y 2010) Revista Geográfica Digital. IGUNNE. Facultad de Humanidades. UNNE. Año 12. No 23. Enero - Junio 2015. ISSN 1668-5180 Resistencia, Chaco.

En: http://hum.unne.edu.ar/revistas/geoweb/default.htm 


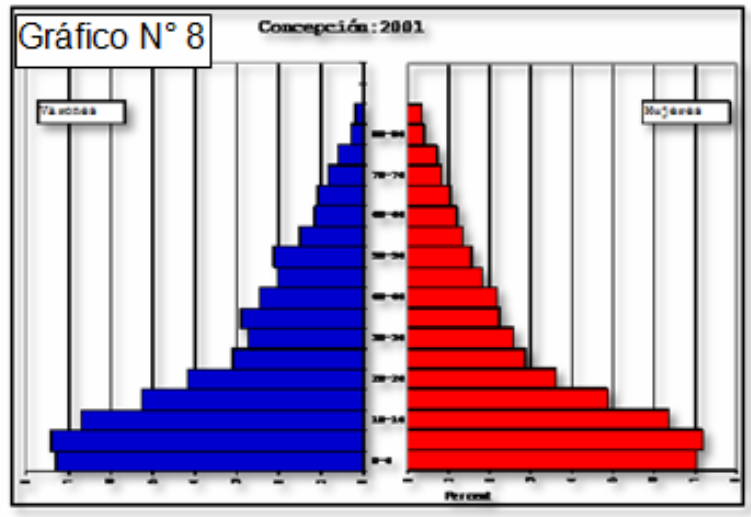

Elaboración propia en base a los datos del INDEC 2001

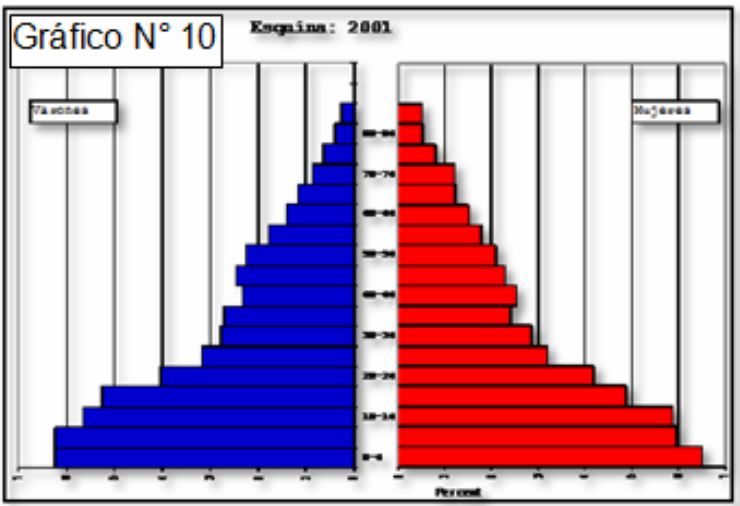

Elaboración propia en base a los datos del INDEC 2001

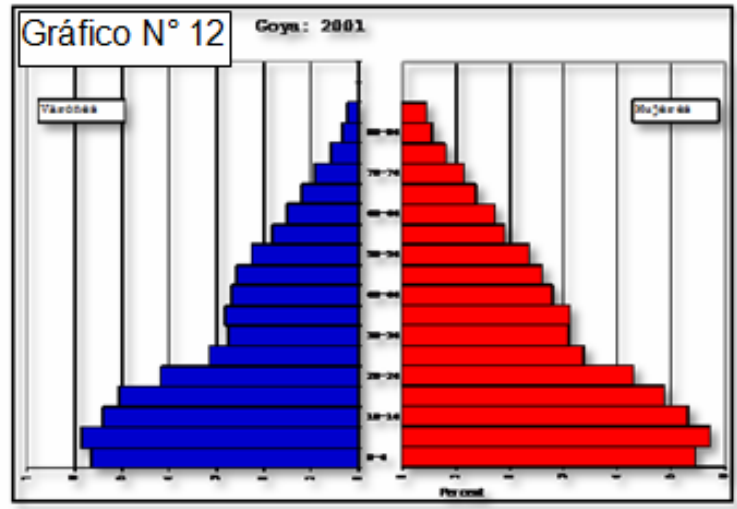

Elaboración propia en base a los datos del INDEC 2010

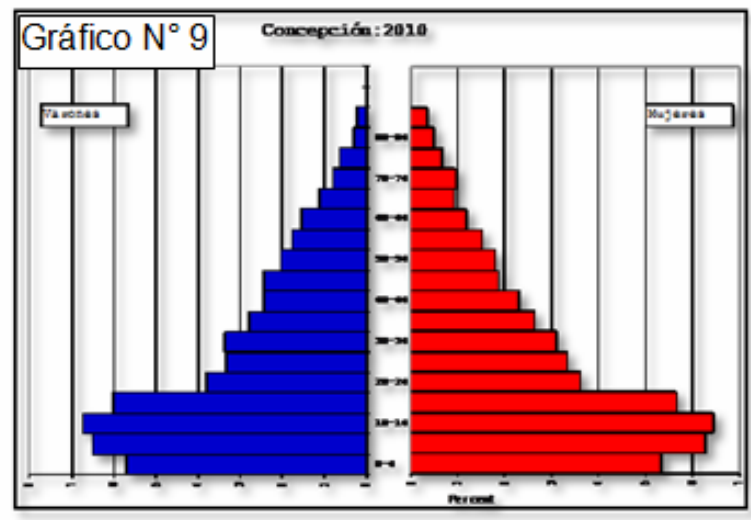

Elaboración propia en base a los datos del INDEC 2010

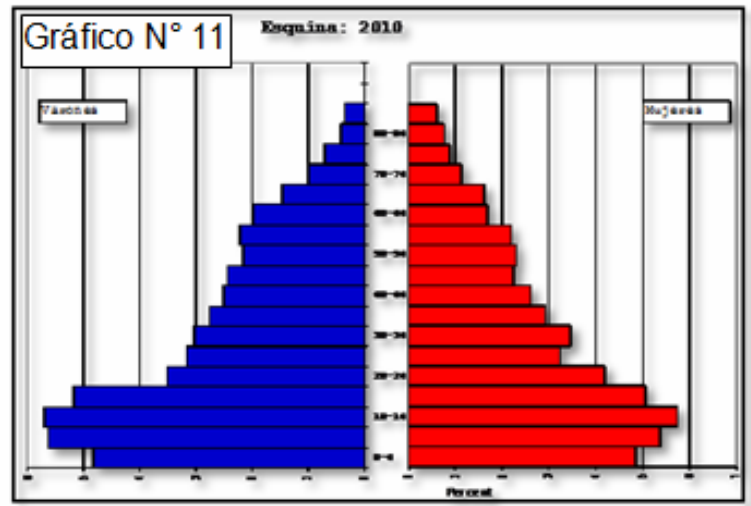

Elaboración propia en base a los datos del INDEC 2010

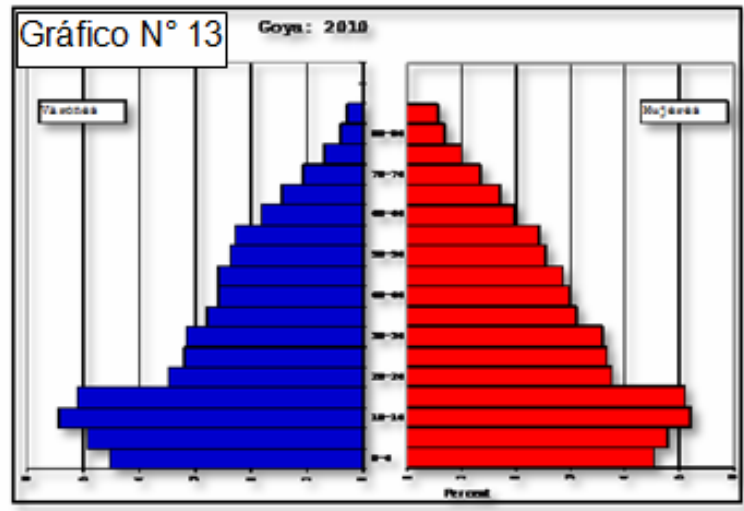

Elaboración propia en base a los datos del INDEC 2010

Publicado en formato digital: Prof. Elsie Araseli Ojeda y Dra. Blanca Elizabeth Ponce. PERFIL DEMOGRÁFICO DE LAS LOMADAS ARENOSAS EN EL TRIÁNGULO NOROCCIDENTAL DE LA PROVINCIA DE CORRIENTES (ARGENTINA): ANÁLISIS EN DOS MOMENTOS CENSALES (2001 y 2010) Revista Geográfica Digital. IGUNNE. Facultad de Humanidades. UNNE. Año 12. No 23. Enero - Junio 2015. ISSN 1668-5180 Resistencia, Chaco.

En: http://hum.unne.edu.ar/revistas/geoweb/default.htm 


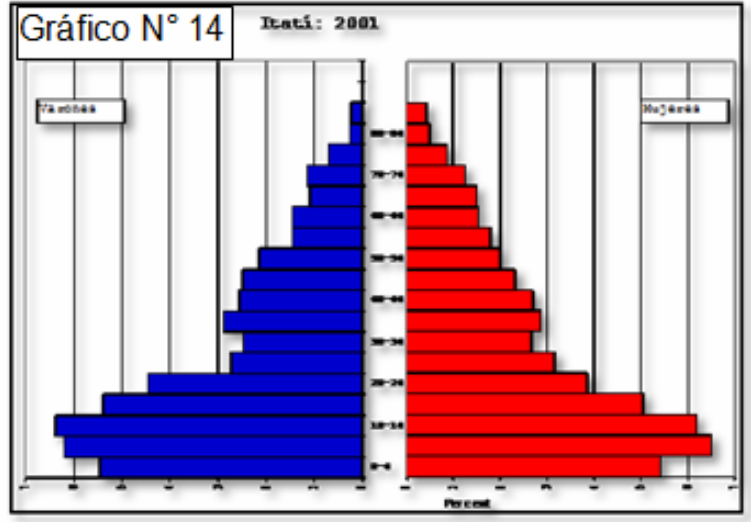

Elaboración propia en base a los datos del INDEC 2010

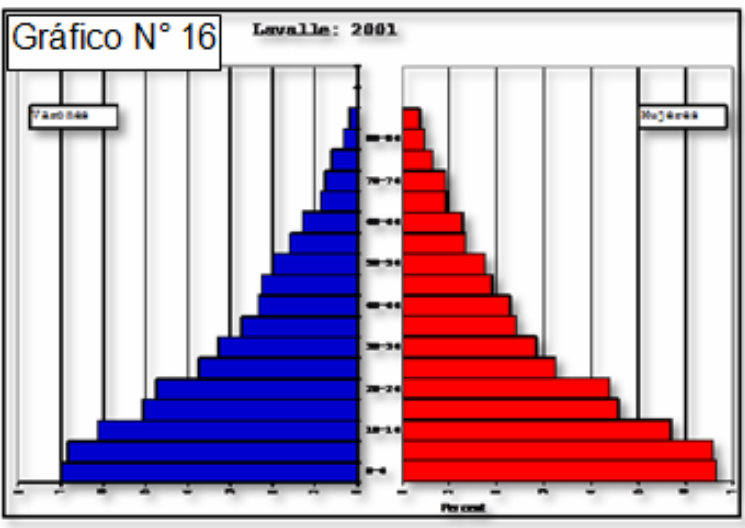

Elaboración propia en base a los datos del INDEC 2010

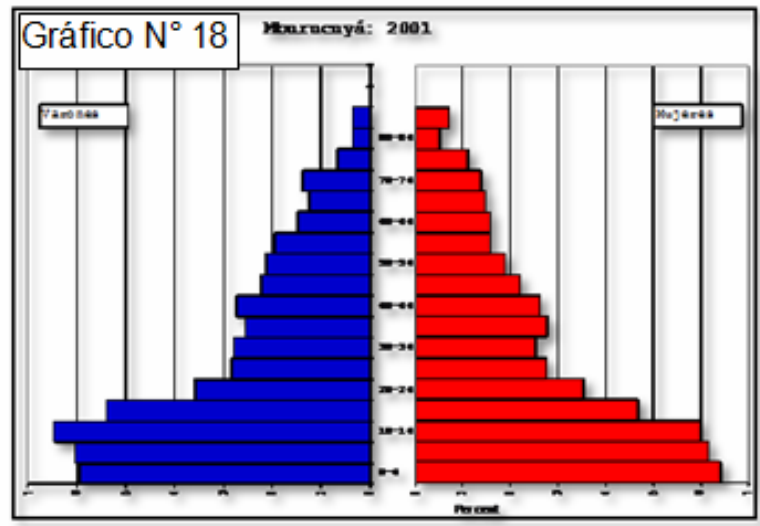

Elaboración propia en base a los datos del INDEC 2001

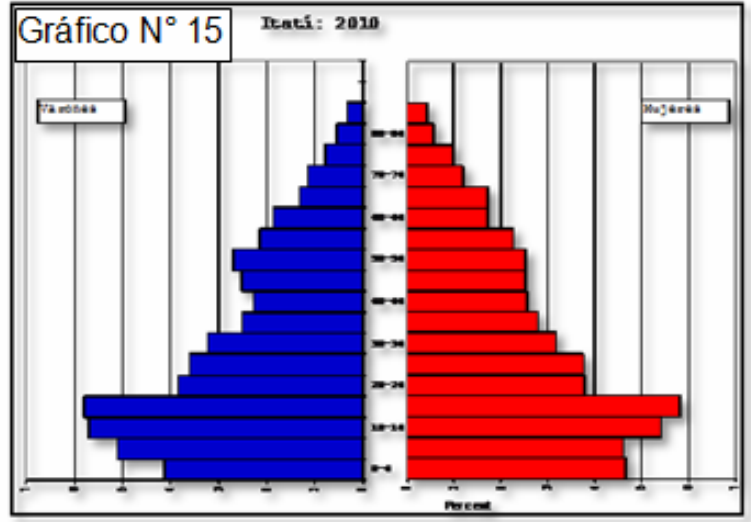

Elaboración propia en base a los datos del INDEC 2010

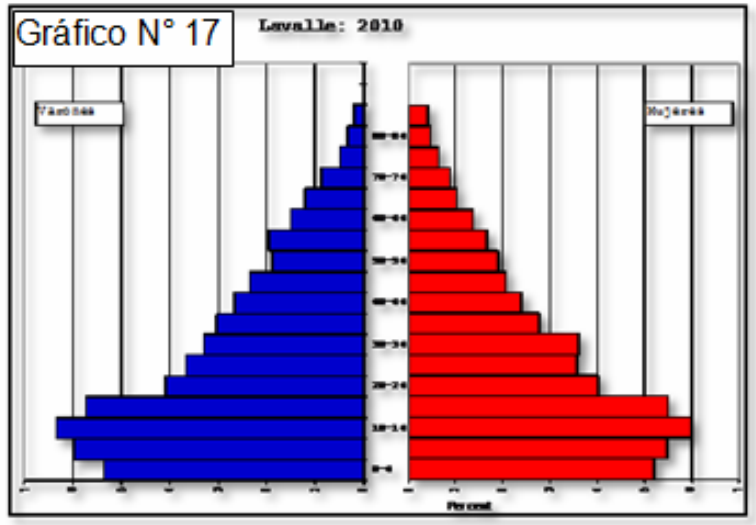

Elaboración propia en base a los datos del INDEC 2010

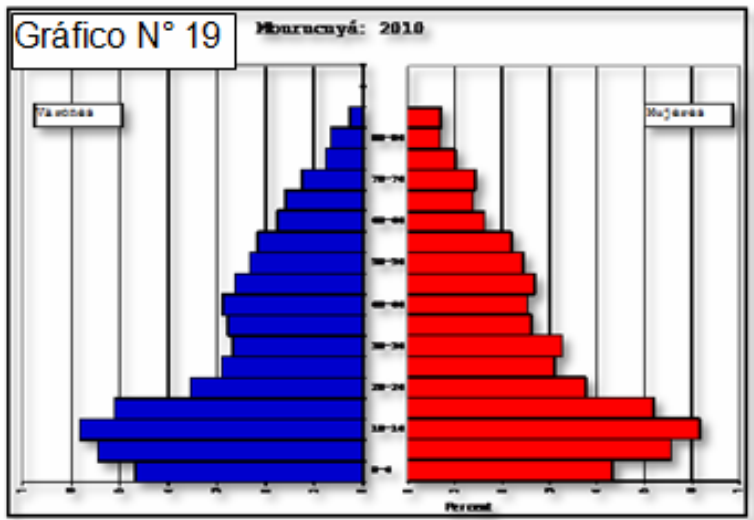

Elaboración propia en base a los datos del INDEC 2010

Publicado en formato digital: Prof. Elsie Araseli Ojeda y Dra. Blanca Elizabeth Ponce. PERFIL DEMOGRÁFICO DE LAS LOMADAS ARENOSAS EN EL TRIÁNGULO NOROCCIDENTAL DE LA PROVINCIA DE CORRIENTES (ARGENTINA): ANÁLISIS EN DOS MOMENTOS CENSALES (2001 y 2010) Revista Geográfica Digital. IGUNNE. Facultad de Humanidades. UNNE. Año 12. No 23. Enero - Junio 2015. ISSN 1668-5180 Resistencia, Chaco.

En: http://hum.unne.edu.ar/revistas/geoweb/default.htm 


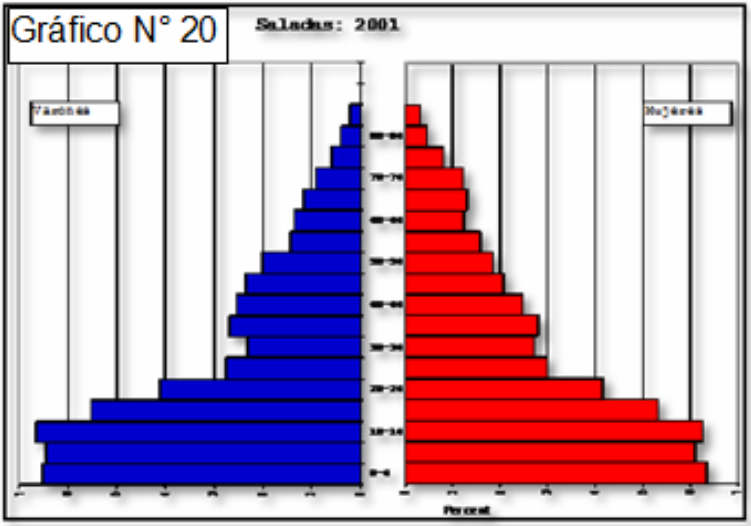

Elaboración propia en base a los datos del INDEC 2001

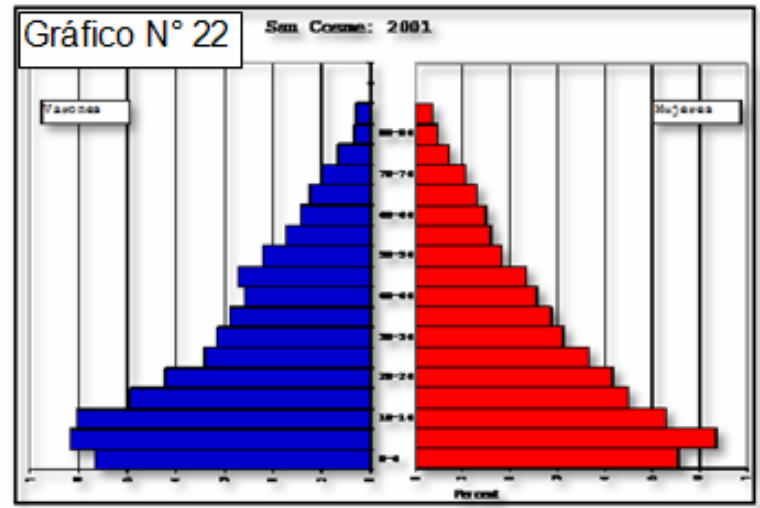

Elaboración propia en base a los datos del INDEC 2001

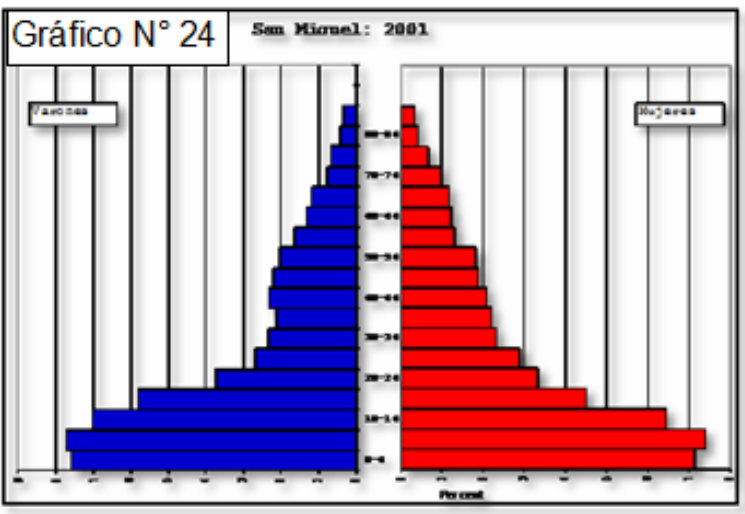

Elaboración propia en base a los datos del INDEC 2001

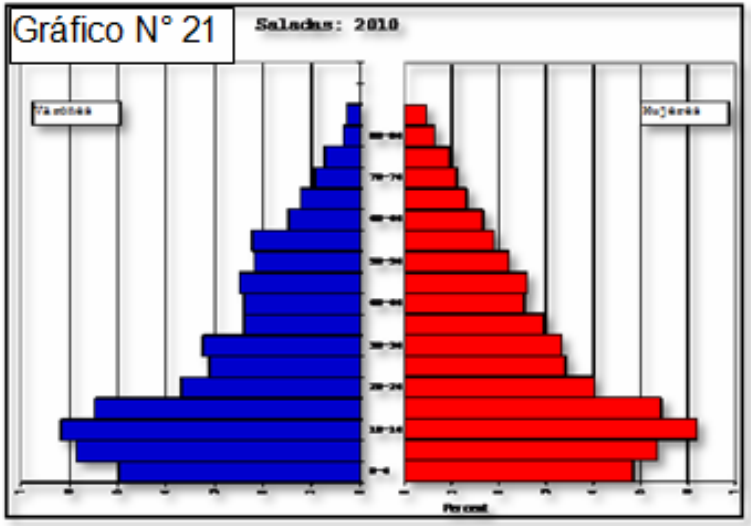

Elaboración propia en base a los datos del INDEC 2010

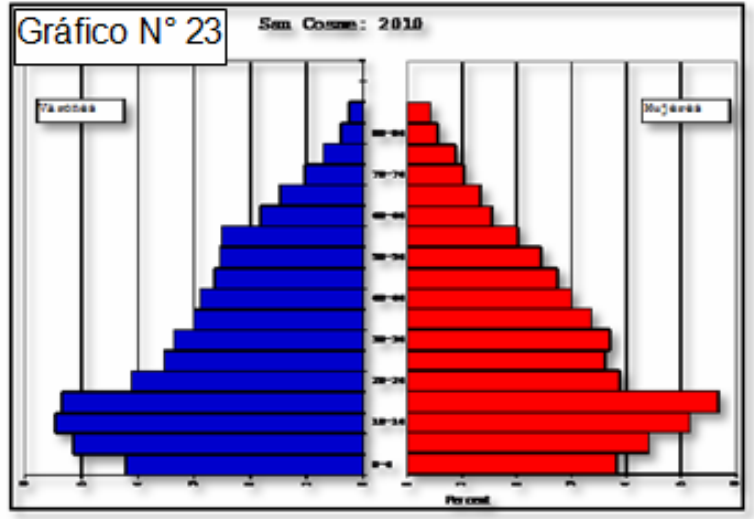

Elaboración propia en base a los datos del INDEC 2010

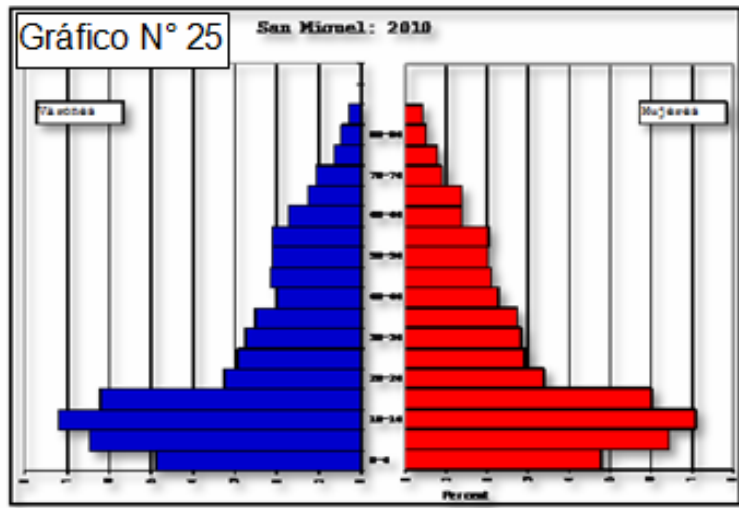

Elaboración propia en base a los datos del INDEC 2010

Publicado en formato digital: Prof. Elsie Araseli Ojeda y Dra. Blanca Elizabeth Ponce. PERFIL DEMOGRÁFICO DE LAS LOMADAS ARENOSAS EN EL TRIÁNGULO NOROCCIDENTAL DE LA PROVINCIA DE CORRIENTES (ARGENTINA): ANÁLISIS EN DOS MOMENTOS CENSALES (2001 y 2010) Revista Geográfica Digital. IGUNNE. Facultad de Humanidades. UNNE. Año 12. No 23. Enero - Junio 2015. ISSN 1668-5180 Resistencia, Chaco.

En: http://hum.unne.edu.ar/revistas/geoweb/default.htm 


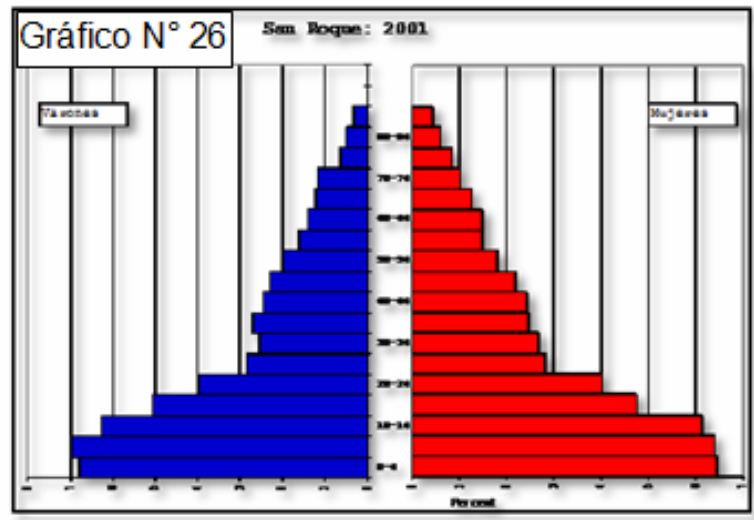

Elaboración propia en base a los datos del INDEC 2001

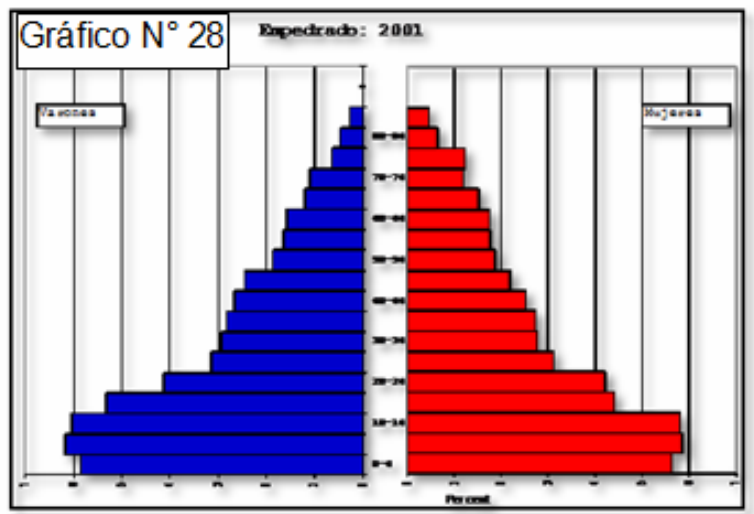

Elaboración propia en base a los datos del INDEC 2001

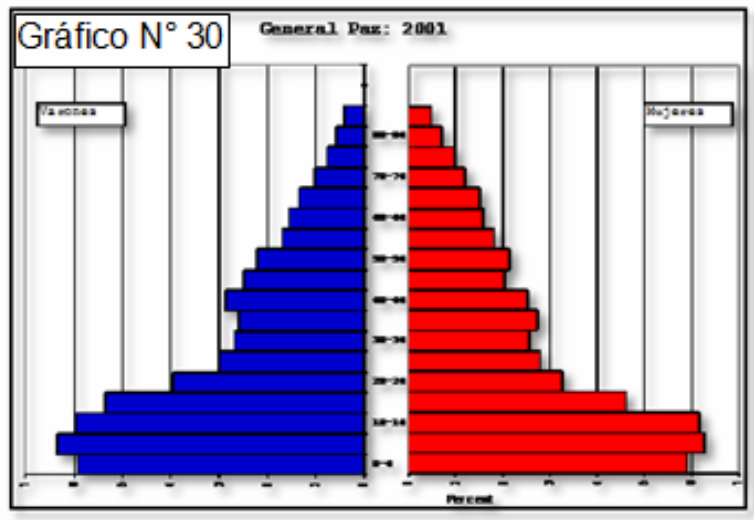

Elaboración propia en base a los datos del INDEC 2001

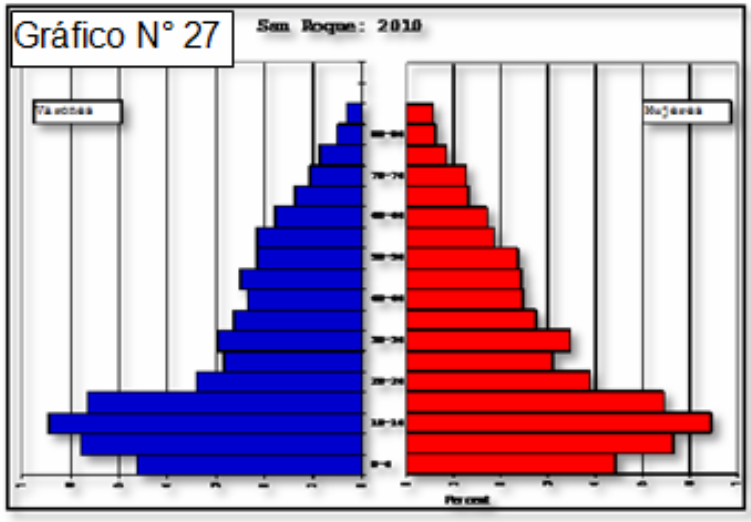

Elaboración propia en base a los datos del INDEC 2010

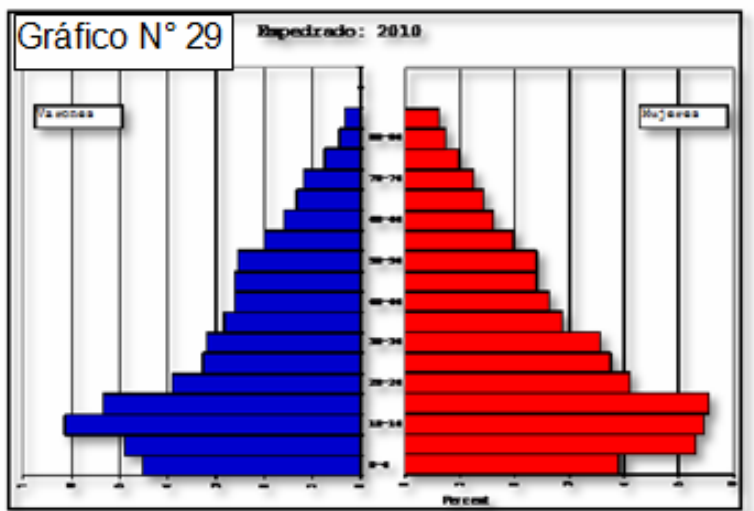

Elaboración propia en base a los datos del INDEC 2010

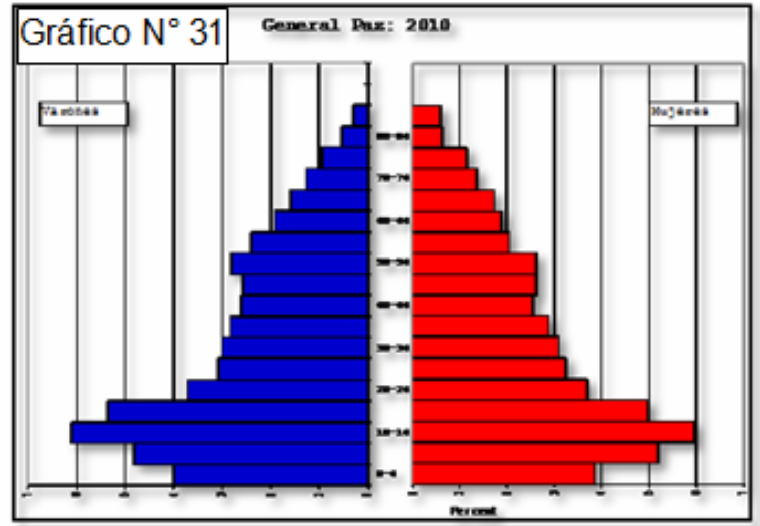

Elaboración propia en base a los datos del INDEC 2010

Publicado en formato digital: Prof. Elsie Araseli Ojeda y Dra. Blanca Elizabeth Ponce. PERFIL DEMOGRÁFICO DE LAS LOMADAS ARENOSAS EN EL TRIÁNGULO NOROCCIDENTAL DE LA PROVINCIA DE CORRIENTES (ARGENTINA): ANÁLISIS EN DOS MOMENTOS CENSALES (2001 y 2010) Revista Geográfica Digital. IGUNNE. Facultad de Humanidades. UNNE. Año 12. No 23. Enero - Junio 2015. ISSN 1668-5180 Resistencia, Chaco.

En: http://hum.unne.edu.ar/revistas/geoweb/default.htm 


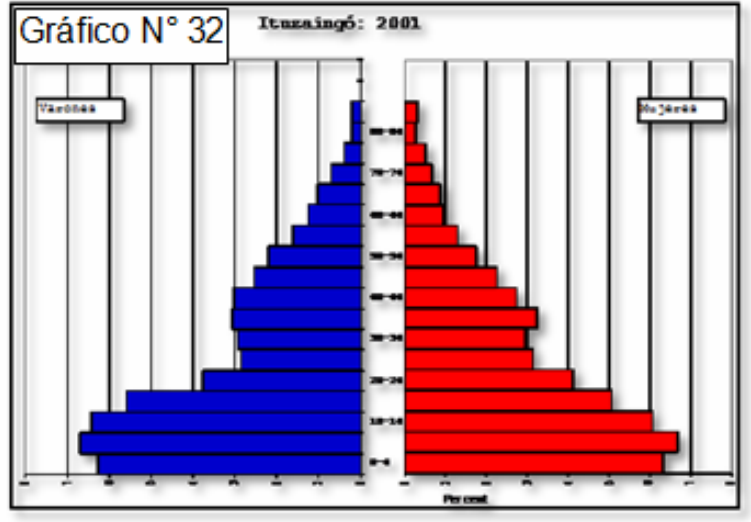

Elaboración propia en base a los datos del INDEC 2001

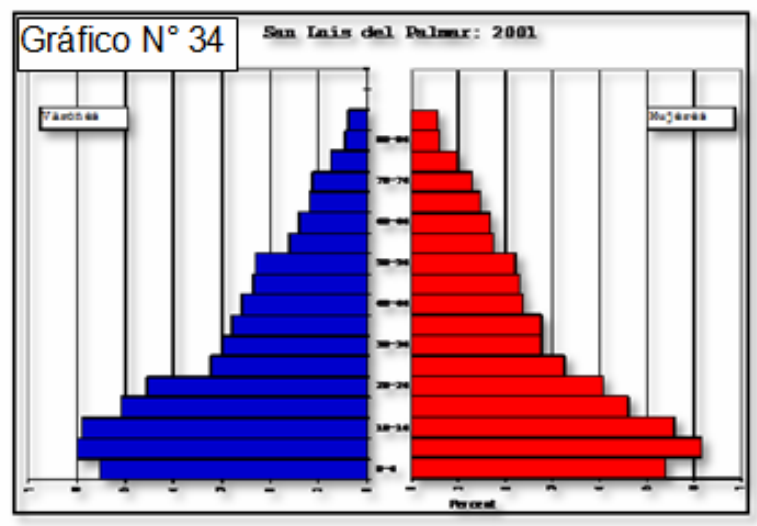

Elaboración propia en base a los datos del INDEC 2001

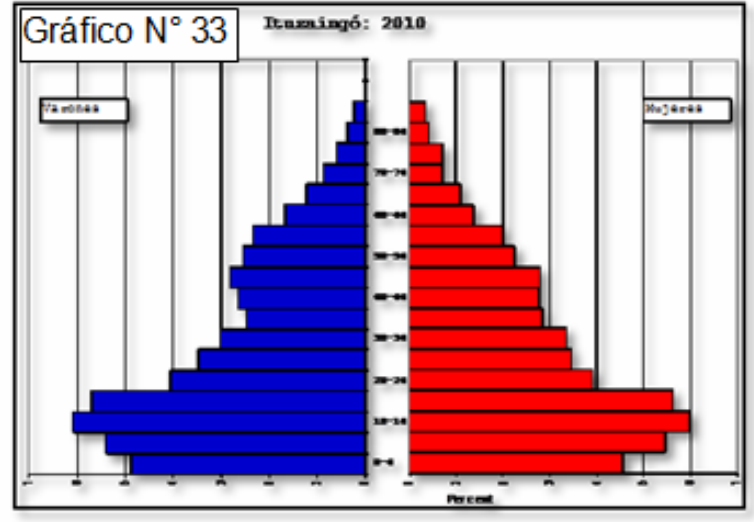

Elaboración propia en base a los datos del INDEC 2010

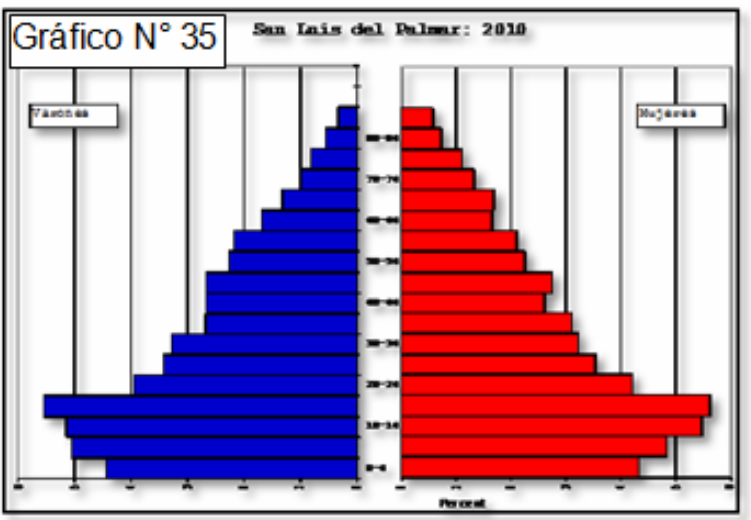

Elaboración propia en base a los datos del INDEC 2010

\section{Grandes grupos de edades}

A continuación se presenta la estructura por edad de la población en los 17 departamentos que integran la Región de Lomadas Arenosas, pudiéndose ver nuevamente, en los dos años analizados, los mismos patrones de comportamiento mencionados anteriormente.

En el año 2001 existen altos porcentajes de población de 0 a 14 años, sobresaliendo los departamentos Concepción y San Miguel con el $42 \%$ y $43 \%$ respectivamente. Por su parte, la población mayor de 65 años, posee valores bajos, distinguiéndose Bella Vista, Capital, Concepción y Lavalle con un $6 \%$. (Ver Gráfico N ${ }^{\circ} 36$ ).

Para el año 2010 nos encontramos con una estructura más envejecida. En consecuencia, el grueso de la población está compuesto por las edades entre 15-64 años, ocupando aproximadamente el 50\% de la estructura. A modo de ejemplo podemos mencionar a: Bella Vista, Capital y San Cosme (Ver Gráfico $\left.N^{\circ} 37\right)$.

Publicado en formato digital: Prof. Elsie Araseli Ojeda y Dra. Blanca Elizabeth Ponce. PERFIL DEMOGRÁFICO DE LAS LOMADAS ARENOSAS EN EL TRIÁNGULO NOROCCIDENTAL DE LA PROVINCIA DE CORRIENTES (ARGENTINA): ANÁLISIS EN DOS MOMENTOS CENSALES (2001 y 2010) Revista Geográfica Digital. IGUNNE. Facultad de Humanidades. UNNE. Año 12. No 23. Enero - Junio 2015. ISSN 1668-5180 Resistencia, Chaco.

En: http://hum.unne.edu.ar/revistas/geoweb/default.htm 
En este contexto, la mayor presencia de población económicamente activa, implica un mayor peso sobre el mercado laboral. De esta manera, la población que se encuentra ocupada, se reparte mayoritariamente entre el sector público y los trabajadores de cuenta propia. Esta situación, deja en evidencia la poca capacidad de generar empleo que presenta el sector privado en esta región, constituyéndose en el principal factor de expulsión durante el periodo más crítico del gobierno neoliberal. Este grupo se caracteriza por su alta heterogeneidad, ya que ampara en su interior una diversidad de formas de empleo y auto-empleo que en función de la estrategia de obtención de los datos los subsume bajo una misma denominación. Con claro predominio de obreros y empleados ocupaciones en relación de dependencia- concentra la población con los mejores niveles educativos, pero también una proporción importante de trabajadores temporarios, entre ellos los incluidos en los planes de empleo. Las cifras que corresponden a este último grupo inciden en la disminución de las cifras del desempleo, dado que figuran en una importante proporción como ocupados plenos, aun cuando desde la perspectiva del empleo su condición sea la precariedad.

El grupo de trabajadores no registrados muestra el predominio en empleos temporarios, sin beneficios sociales y una alta vinculación con tales situaciones, en las que se encuentran preferentemente los más jóvenes y las mujeres. Mientras tanto, los trabajadores registrados representan el $41.2 \%$ de los ocupados, estando una proporción importante vinculada con el empleo estatal (Pérez Rubio, 2013).

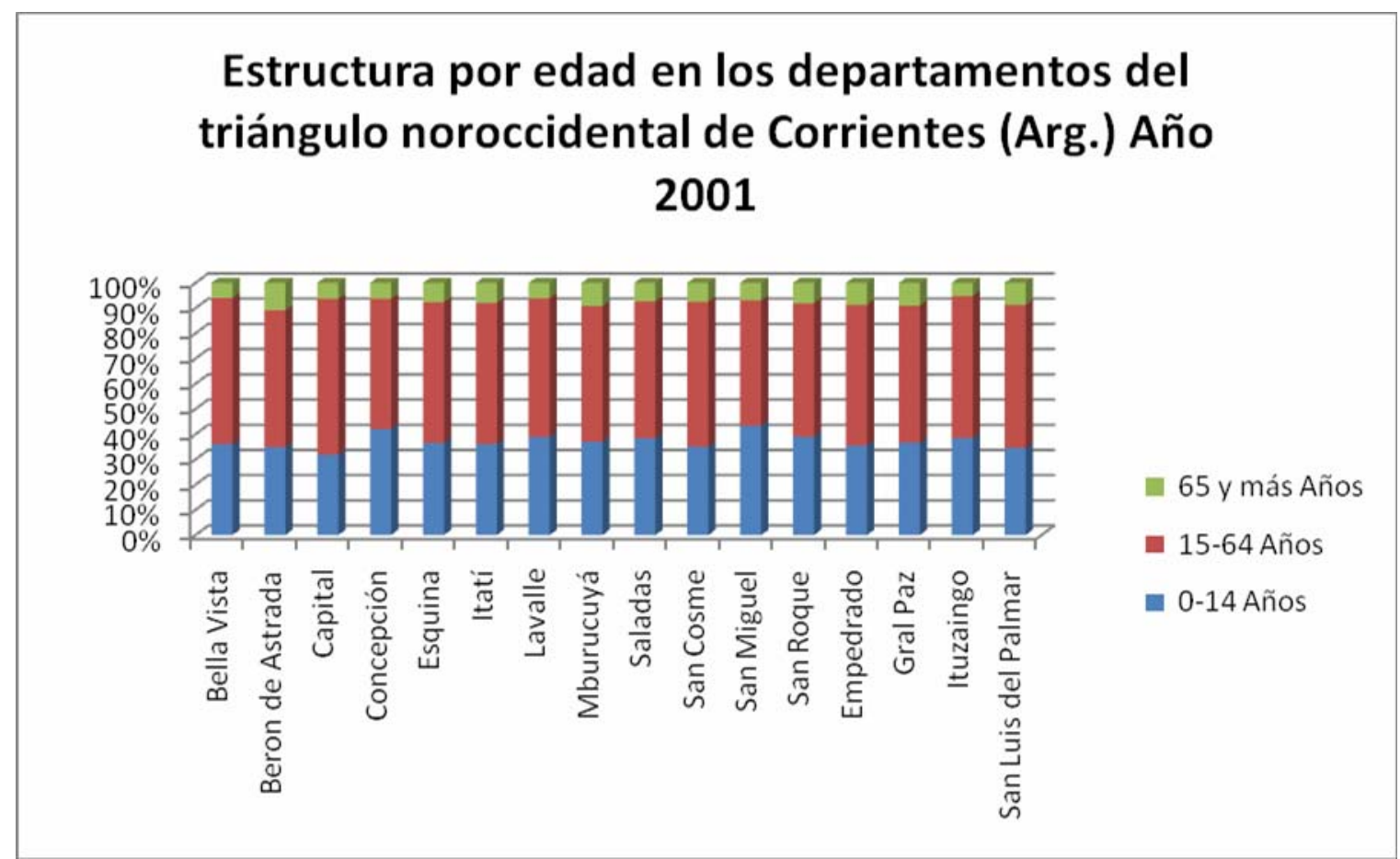

Fuente: Elaboración propia en base a los datos del INDEC 2001.

Grafico $N^{\circ} 36$

Publicado en formato digital: Prof. Elsie Araseli Ojeda y Dra. Blanca Elizabeth Ponce. PERFIL DEMOGRÁFICO DE LAS LOMADAS ARENOSAS EN EL TRIÁNGULO NOROCCIDENTAL DE LA PROVINCIA DE CORRIENTES (ARGENTINA): ANÁLISIS EN DOS MOMENTOS CENSALES (2001 y 2010) Revista Geográfica Digital. IGUNNE. Facultad de Humanidades. UNNE. Año 12. No 23. Enero - Junio 2015. ISSN 1668-5180 Resistencia, Chaco.

En: http://hum.unne.edu.ar/revistas/geoweb/default.htm 


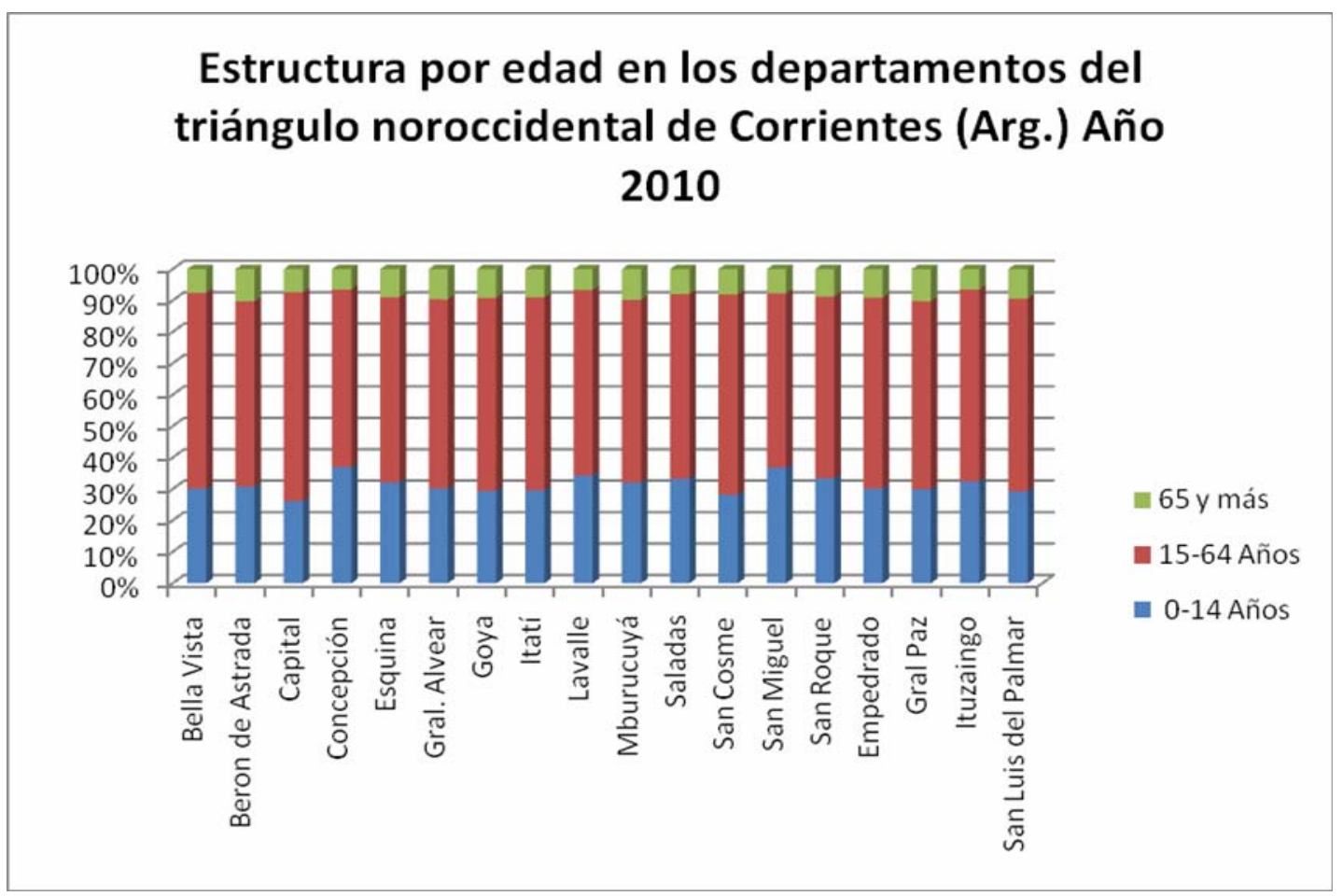

Fuente: Elaboración propia en base a los datos del INDEC 2010

Gráfico $\mathbf{N}^{\circ} 37$

\section{Índice de Masculinidad}

Entendemos por Índice de Masculinidad a la proporción de hombres frente a la de mujeres en una población determinada.

Esta variable influye directamente sobre la estructura por edad y sexo antes analizada en las pirámides de población, ya que la diferencia de sexo genera desigualdad en la esperanza de vida, en la morbilidad, y en la mortalidad.

De acuerdo con la información censal del año 2001 en la Región de Lomadas Arenosas (ver Mapa $\mathrm{N}^{\circ} 2$ ) existen 97 varones por cada 100 mujeres. No obstante podemos mencionar algunos departamentos cuyos índices de masculinidad son elevados, tales son los casos de: Lavalle (107 varones por cada 100 mujeres) Concepción (108 varones por cada 100 mujeres) San Miguel (108 varones por cada 100 mujeres) Berón de Astrada (106 varones por cada 100 mujeres).

En el año 2010 el índice de masculinidad desciende a 95 hombres por cada 100 mujeres en la región (ver Mapa $\mathrm{N}^{\circ} 3$ ), destacándose los departamentos de San Cosme, Berón de Astrada, Lavalle, Concepción e Ituzaingó con 101, 105, 104, 106 y 102 varones por cada 100 mujeres respectivamente.

Todos estos departamentos con altos índices de masculinidad, se caracterizan por tener una gran participación en las actividades primarias, especialmente en la agricultura, floricultura y forestación, lo que indicaría una gran demanda de mano de obra masculina para la realización de dichas tareas.

Por otra parte, el departamento Capital es quien tiene el menor índice de masculinidad para ambos momentos censales (92 varones por cada 100 mujeres), situación que podría estar relacionada con la tercerización de las actividades económicas.

Publicado en formato digital: Prof. Elsie Araseli Ojeda y Dra. Blanca Elizabeth Ponce. PERFIL DEMOGRÁFICO DE LAS LOMADAS ARENOSAS EN EL TRIÁNGULO NOROCCIDENTAL DE LA PROVINCIA DE CORRIENTES (ARGENTINA): ANÁLISIS EN DOS MOMENTOS CENSALES (2001 y 2010) Revista Geográfica Digital. IGUNNE. Facultad de Humanidades. UNNE. Año 12. No 23. Enero - Junio 2015. ISSN 1668-5180 Resistencia, Chaco.

En: http://hum.unne.edu.ar/revistas/geoweb/default.htm 
Revista Geográfica Digital. IGUNNE - Instituto de Geografía. Facultad de Humanidades. UNNE. Año 12. No 23. Enero - Junio 2015. ISSN 1668-5180 Resistencia, Chaco, Argentina
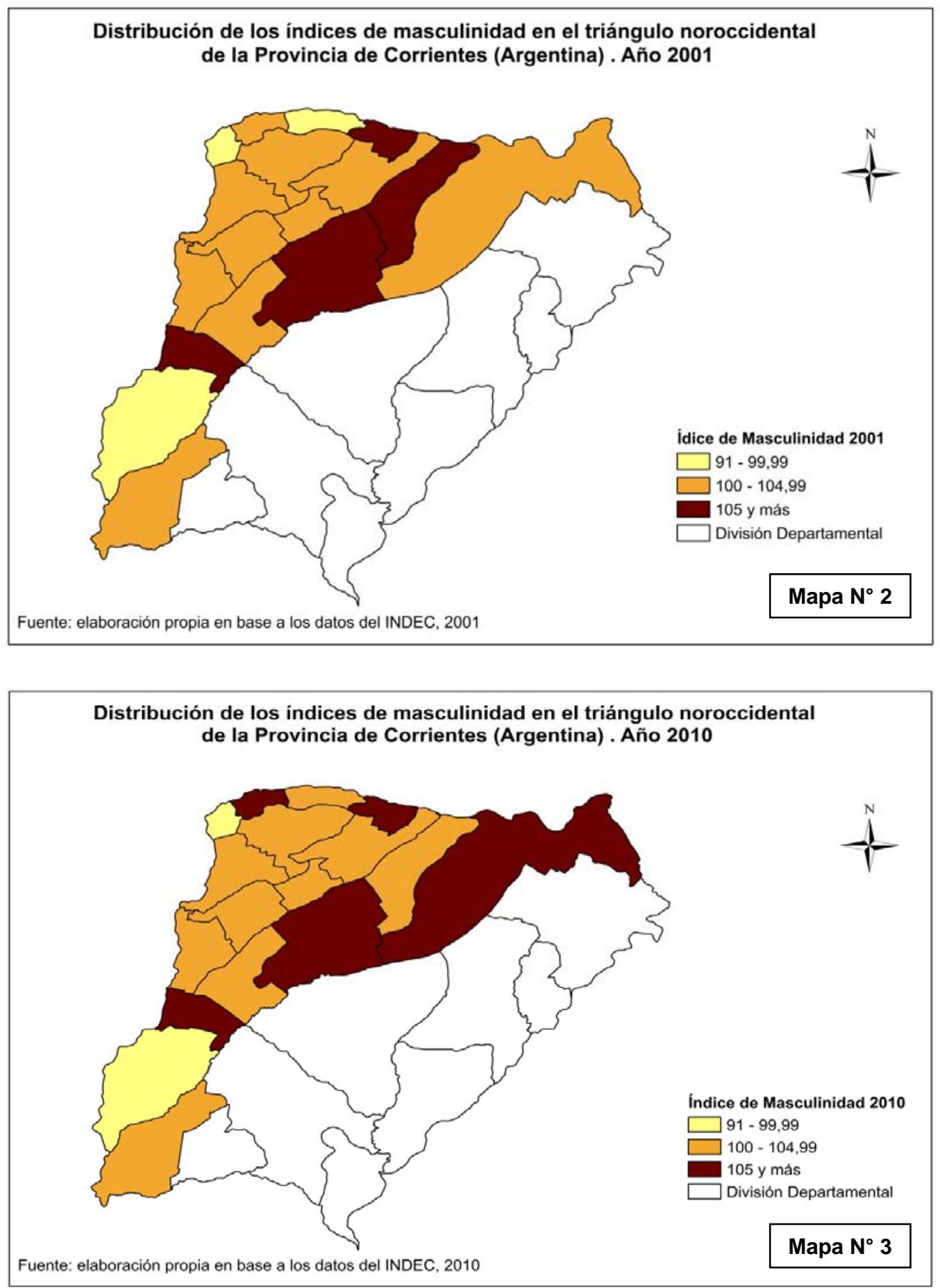

Publicado en formato digital: Prof. Elsie Araseli Ojeda y Dra. Blanca Elizabeth Ponce. PERFIL DEMOGRÁFICO DE LAS LOMADAS ARENOSAS EN EL TRIÁNGULO NOROCCIDENTAL DE LA PROVINCIA DE CORRIENTES (ARGENTINA): ANÁLISIS EN DOS MOMENTOS CENSALES (2001 y 2010) Revista Geográfica Digital. IGUNNE. Facultad de Humanidades. UNNE. Año 12. No 23. Enero - Junio 2015. ISSN 1668-5180 Resistencia, Chaco.

En: http://hum.unne.edu.ar/revistas/geoweb/default.htm 
Revista Geográfica Digital. IGUNNE - Instituto de Geografía. Facultad de Humanidades. UNNE. Año 12. NN$^{\circ}$ 23. Enero - Junio 2015. ISSN 1668-5180 Resistencia, Chaco, Argentina

\section{Conclusiones}

La evolución de los departamentos estudiados a lo largo de la historia, ha sido condicionada por los sucesos políticos y económicos que determinaron el crecimiento poblacional, dando como resultado la expulsión de población en los sectores con escasa capacidad para satisfacer las demandas de los habitantes. Éstos fueron captados por los centros urbanos más grandes como por ejemplo la Capital correntina, que como consecuencia, aumentó su población económicamente activa, tal como lo reflejan las pirámides de población analizadas.

La ciudad antes mencionada, ha duplicado su población en solo 40 años (137.823 habitantes en 1970 y 358.223 habitantes en el 2010). La razón se debe a los procesos migratorios que se produjeron desde el interior provincial hacia la Capital, en búsqueda de mejores condiciones de vida.

En este contexto, el tipo de pirámide que predomina en esta región es la Triangular, con una base ancha y un progresivo angostamiento hacia la cúspide, no obstantes existen excepciones, tal es el caso de Berón de Astrada con una pirámide de forma irregular, donde se advierte una notable falta de población en el grupo correspondiente a las edades económicamente activas. Como se mencionara anteriormente, esta pérdida de población está relacionado a las emigraciones producidas hacia el departamento Capital, donde las diferentes oportunidades que ofrece la ciudad, como las universidades públicas y/o privadas e institutos terciarios, actúan como polo atrayente, no solo de la provincia sino de la región, de igual manera, podría estar relacionado a la mayor oferta en el mercado laboral.

Con respecto a la estructura por edad y sexo en los dos momentos censales, podemos decir que se mantienen constantes, aunque observamos un incipiente grado de madurez de la población, expresado a través de los bajos índices de natalidad, en el año 2001.

Si consideramos únicamente la composición por edad de la población, advertimos un aumento de la población en edad económicamente activa para el año 2010, generando un mayor peso sobre el mercado laboral, que se reparte mayoritariamente entre el sector público y los trabajadores de cuenta propia, reflejando la escasa capacidad de generar empleo que tiene el sector privado.

Por otra parte aumenta el porcentaje de los adultos mayores, relacionado con la disminución de la mortalidad y el aumento de la esperanza de vida.

Finalmente los fuertes índices de masculinidad en el centro y norte de la provincia, estaría relacionado con las actividades que estos departamentos realizan, debido a la gran participación en las actividades primarias, especialmente en la agricultura, floricultura y forestación, lo que indicaría una gran demanda de mano de obra masculina para la realización de dichas tareas.

Publicado en formato digital: Prof. Elsie Araseli Ojeda y Dra. Blanca Elizabeth Ponce. PERFIL DEMOGRÁFICO DE LAS LOMADAS ARENOSAS EN EL TRIÁNGULO NOROCCIDENTAL DE LA PROVINCIA DE CORRIENTES (ARGENTINA): ANÁLISIS EN DOS MOMENTOS CENSALES (2001 y 2010) Revista Geográfica Digital. IGUNNE. Facultad de Humanidades. UNNE. Año 12. No 23. Enero - Junio 2015. ISSN 1668-5180 Resistencia, Chaco.

En: http://hum.unne.edu.ar/revistas/geoweb/default.htm 
Revista Geográfica Digital. IGUNNE - Instituto de Geografía. Facultad de Humanidades. UNNE. Año 12. Nº 23. Enero - Junio 2015. ISSN 1668-5180 Resistencia, Chaco, Argentina

\section{Bibliografía}

- Carnevali, R. (1994). "Fitogeografía de la Provincia de Corrientes". Ed. Litocolor, Asunción.

- Frenguelli, J. (1924). "Apuntes geomorfológicos sobre el interior de la provincia de Corrientes". Casa Coni, Buenos Aires.

- Foschiatti, Ana M. (2013) "La Población de Corrientes: su evolución y crecimiento". En Ramirez, Liliana (et.al.) "Corrientes en Cifras. Recopilación y compilación estadística para la interpretación de la situación actual". ConTexto Libros. Resistencia. Pp 23-29

- $\quad$ Foschiatti, Ana M.; Bolsi, Alfredo (1990) "La Población de la ciudad de Corrientes entre 1588 y 1980" en Demográfica. Revista de Estudios de Población $N^{\circ} 2$. Editorial GRAFOS. Resistencia, Chaco. Pp 1 - 94

- Foschiatti, Ana M. (1992) "Principales tendencias del poblamiento en el nordeste argentino" en Demográfica. Revista de Estudios de Población № 7. Editorial GRAFOS. Resistencia, Chaco. Pp 1-15.

- Iriondo, M. y Paira, A. (2007). "Geomorphology. The Middle Paraná River - Limnology of a Subtropical Wetland". Springer-Verlag Berlin Heidelberg.

- Meichtry, Norma (1980). "Corrientes: espacio, población y migraciones". En Estudios Regionales $\mathrm{N}^{\circ} 14$. IIGHI, Corrientes.

- Perez Rubio, Ana M. (2013) "Algunas consideraciones en torno a la estructura social y ocupacional de la Provincia de Corrientes". En Ramírez, Liliana (et. al) "Corrientes en Cifras. Recopilación y compilación estadística para la interpretación de la situación actual". ConTexto Libros. Resistencia. Pp 31 - 36

- Popolizio, E. (1984). "Importancia de la fotointerpretación Geomorfológica en las Obras de Ingeniería de las Llanuras". En Geociencias XII. Centro de Geociencias Aplicadas. UNNE. Resistencia, Chaco, pp $11-12$.

\section{- FUENTES}

- Instituto Nacional de Estadísticas y Censos. (INDEC). 1970. "Censo Nacional de Población y Vivienda de la Provincia de Corrientes, 1970". INDEC. Buenos Aires.

- Instituto Nacional de Estadísticas y Censos. (INDEC). 1980. "Censo Nacional de Población y Vivienda de la Provincia de Corrientes, 1980". INDEC. Buenos Aires.

- Instituto Nacional de Estadísticas y Censos. (INDEC). 1991. "Censo Nacional de Población y Vivienda de la Provincia de Corrientes, 1991". INDEC. Buenos Aires.

- Instituto Nacional de Estadísticas y Censos. (INDEC). 2001. "Censo Nacional de Población, Hogares y Vivienda de la Provincia de Corrientes, 2001". INDEC. Buenos Aires.

- Instituto Nacional de Estadísticas y Censos. (INDEC). 2010. "Censo Nacional de Población, Hogares y Vivienda de la Provincia de Corrientes, 2010". INDEC. Buenos Aires.

Publicado en formato digital: Prof. Elsie Araseli Ojeda y Dra. Blanca Elizabeth Ponce. PERFIL DEMOGRÁFICO DE LAS LOMADAS ARENOSAS EN EL TRIÁNGULO NOROCCIDENTAL DE LA PROVINCIA DE CORRIENTES (ARGENTINA): ANÁLISIS EN DOS MOMENTOS CENSALES (2001 y 2010) Revista Geográfica Digital. IGUNNE. Facultad de Humanidades. UNNE. Año 12. No 23. Enero - Junio 2015. ISSN 1668-5180 Resistencia, Chaco.

En: http://hum.unne.edu.ar/revistas/geoweb/default.htm 